\title{
Efficacy and safety of Chinese herbal medicine for chronic prostatitis associated with damp-heat and blood-stasis syndromes: a meta-analysis and literature review
}

\author{
This article was published in the following Dove Press journal: \\ Patient Preference and Adherence \\ 19 September 2016 \\ Number of times this article has been viewed
}

\section{Zhiqiang Wang' \\ Lei Yuan' \\ Yongchuan Wang ${ }^{2}$ \\ Baizhi Yang' \\ Xiaohong Dong' \\ Zhaowang Gao}

'Department of Urology, Shouguang Hospital of Traditional Chinese Medicine, Shouguang, ${ }^{2}$ Department of Urology, Weifang Traditional Chinese Hospital, Weifang, ${ }^{3}$ Department of Urology, Shandong University of Traditional Chinese Medicine Affiliated Hospital, Shandong, People's Republic of China
Correspondence: Zhiqiang Wang Department of Urology, Shouguang Hospital of Traditional Chinese Medicine, Shouguang 262700, People's Republic of China Tel +86 I37 916। 2182 Email TCMwangzhiqiang@163.com
Objective: The aim of this meta-analysis and systematic review is to evaluate the safety and efficacy of Chinese herbal medicine (CHM) for chronic prostatitis (CP) associated with dampheat and blood-stasis syndromes.

Methods: An electronic search of 13 databases up to May 2016 was screened to identify randomized controlled trials comparing the safety and efficacy of CHM for the treatment of CP associated with damp-heat and blood-stasis syndromes. Studies reporting on effective rates, adverse events, National Institutes of Health chronic prostatitis symptom index (NIH-CPSI) scores, and symptom index of Chinese medicine for chronic prostatitis (SI-CM) scores as outcomes were included in the analysis. Data were analyzed by fixed- or random-effect models using the Review Manager software.

Results: Thirteen articles with the modified Jadad score $\geq 4$ were identified. It was found that CHM was superior to placebo in increasing the efficacy (odds ratio: 6.72, 95\% confidence interval $[\mathrm{CI}]: 2.78-9.48, P<0.00001$ ) and reducing the SI-CM scores (standardized mean difference: $-1.08,95 \% \mathrm{CI}:-1.35$ to $-0.81, P<0.00001)$. Oral CHMs were significantly more effective than placebo at reducing NIH-CPSI scores, with a mean difference of $-1.39(95 \%$ CI: -1.87 to $-0.92, P<0.00001)$. Nevertheless, no significant differences were found between Prostant and placebo (standardized mean difference: $-0.23,95 \% \mathrm{CI}:-0.46$ to $0.01, P=0.06$ ). The frequency of adverse events associated with oral CHM was similar to that associated with placebo (risk ratio: $1.36,95 \% \mathrm{CI}: 0.72-2.55, P=0.34$ ) and less than that associated with Prostant (risk ratio: $1.63,95 \% \mathrm{CI}: 1.14-2.34, P=0.008$ ).

Conclusion: Our novel analysis demonstrates that CHM ranks highest in terms of improvement of CP associated with damp-heat and blood-stasis syndromes. While Prostant showed some efficacy in this disorder, it was associated with a smaller reduction in NIH-CPSI scores. In conclusion, CHM monotherapy is safe and effective for the treatment of $\mathrm{CP}$ associated with damp-heat and blood-stasis syndromes.

Keywords: chronic prostatitis, meta-analysis, damp-heat and blood-stasis syndromes, traditional Chinese medicine

\section{Introduction}

Chronic prostatitis (CP), a frequently occurring disease with a complex and heterogeneous etiology, is characterized by high prevalence, frequent recurrence, low cure rate, and severe impairment of quality of life. ${ }^{1}$

In many Asian countries, particularly in the People's Republic of China, Chinese herbal medicine (CHM) is widely used as an alternative or complement to conventional 
phytotherapy and medication. ${ }^{2}$ According to the theory of typical traditional Chinese medicine (TCM), all the related symptoms and signs in a certain disease phase are generalized to a syndrome ("Zheng" in Chinese pinyin), which is the basic unit and a key concept of TCM. ${ }^{3}$ Syndrome is usually evaluated through a comprehensive analysis of clinical signs and symptoms. To understand and treat CP, TCM combines syndrome differentiation with disease differentiation. Syndrome differentiation is used to identify different types of a single disease to create a specific treatment plan. This approach leads to the identification of multiple syndromes associated with CP; damp-heat and blood-stasis syndromes are the most common syndromes related to this disease. ${ }^{4-6}$ There are multiple approaches in TCM for the treatment of $\mathrm{CP}$, including dispersing liver-qi and alleviating pain, ${ }^{7}$ clearing heat and removing dampness, ${ }^{8}$ and activating blood to dissolve stasis. ${ }^{9}$ Such flexible and diverse therapies in TCM highlight the advantages of personal treatment for CP, according to the individual patient's condition. ${ }^{10}$

Most systematic reviews have reported on the efficacy and safety associated with different CHMs, including bloodactivating and stasis-dissolving medicines ${ }^{11}$ and heat-clearing and damp-removing medicines ${ }^{12}$ for the treatment of $\mathrm{CP}$. However, at the heart of TCM is the goal to understand the differences in pathogenesis and underlying syndromes responsible for a particular disease. CHM should be specifically corresponded with a syndrome, not a disease, and serious side effects could be caused by the abuse or misuse without any consideration of the syndrome differentiation. Thus, we performed a systematic review to evaluate the efficacy and adverse events associated with CHM in men suffering from CP associated with damp-heat and blood-stasis syndromes.

Although CHM has been widely used as an effective alternative for the treatment of CP associated with damp-heat and blood-stasis syndromes, it is still necessary to systematically review and evaluate current evidence from available randomized controlled trials (RCTs) to examine the efficacy and side effects of CHM for the treatment of CP associated with damp-heat and blood-stasis syndromes.

\section{Methods}

This study was performed using the Preferred Reporting Items for Systematic Review and Meta-analyses Statement (PRISMA). ${ }^{12}$

\section{Study selection}

Types of studies

All the RCTs reporting the application of CHM for the treatment of CP associated with damp-heat and blood-stasis syndromes were involved, without limitations on language or publication.

\section{Types of participants}

All the participants enrolled in this study had to meet the following diagnostic criteria: 1) patients meet the diagnostic criteria of CP associated with damp-heat and blood-stasis syndromes for at least 3 months; 2) administration of a pharmacologic intervention to more than ten $\mathrm{CP}$ patients for at least 4 weeks; 3 ) use of a randomized, double-blind, placebo-controlled, parallel-group, or crossover designed study design; and 4) a standardized symptom questionnaire National Institutes of Health chronic prostatitis symptom index (NIH-CPSI) was used as outcome measures criteria of global status or individual symptoms. Patients with benign prostatic hyperplasia, prostate cancer, severe heart disease, severe respiratory disease, severe kidney disease, severe liver disease, severe hematopoietic system disease, or mental disorder were excluded. If the trials did not elaborate the definitions of CP and TCM syndrome but simply stated that the included subjects were CP associated with dampheat and blood-stasis syndromes, they were also included. No limitations on age or ethnicity of the participants were predefined.

\section{Types of interventions}

Patients were randomized into either a CHM (oral or suppository) group or a control group. RCTs comparing CHM versus placebo, no intervention, or Western medicine were included. Studies were excluded if other complementary and alternative medicine therapies beyond CHM, including acupuncture, cupping, moxibustion, Tai Chi, Qigong, massage, yoga, and aromatherapy, were used in either the treatment group or the control group; treatment duration was required to be at least 4 weeks.

\section{Types of outcome measures}

The effective rate was one of the primary outcomes and was most often defined as the proportion of subjects who had $\mathrm{a} \geq 30 \%$ reduction in NIH-CPSI score or $\geq 30 \%$ reduction in number of white blood cells in expressed prostatic secretions. Adverse events (either all-cause or drug related) were also considered as primary outcomes. Secondary outcomes included NIH-CPSI score and symptom index of Chinese medicine for chronic prostatitis (SI-CM) score.

\section{Search strategy}

We searched PubMed, Cochrane Central Register of Controlled Trials, Embase, Cumulative Index to Nursing and Allied 
Health Literature, ISI Web of Science, Allied and Complementary Medicine Database, KoreaMed Database, Scopus, J-STAGE, and Google Scholar from inception to May 15, 2016, using the grouped MeSH term and free text ("Chronic Prostatitis" OR “damp-heat" OR "blood-stasis" OR “dampheat and blood-stasis" OR "traditional Chinese medicine" OR "herbal medicine"). The search also included Wanfang data, Chinese Biomedical Literature Database, VIP medicine information system, and China National Knowledge Infrastructure ("man xing qian lie xian yan" OR "shi re yu zu" OR "shireyuzu" as Chinese pinyin terms). Additionally, Chinese clinical trial registry and international clinical trial registry of the US National Institutes of Health were searched to identify all the relevant ongoing or unpublished clinical trials.

\section{Study selection and data extraction}

The reviewers (ZW and LY) independently screened the literature, identified eligible studies, and extracted data using a standard form. They were then further assessed for the final analysis. Studies that were not included were also listed with reasons for exclusion (eg, only an abstract was presented, repeat publications, and studies without control groups). If the data in an article were insufficient, one reviewer (ZW) requested additional information by contacting the corresponding author by e-mail. Then, the extracted data were reviewed by the second reviewer (LY). All disagreements were resolved by reaching a consensus between the two reviewers or through arbitration by another reviewer $(Z G)$.

\section{Quality assessment}

The quality of the studies was evaluated by the modified Jadad scores. ${ }^{13}$ The risk of bias was assessed using the tool developed by the Cochrane collaboration. The Consolidated Standards for Reporting Trials of traditional Chinese medicine (CONSORT for TCM) was used to evaluate reporting quality. ${ }^{14}$

\section{Data synthesis}

Our statistical analyses were conducted using IBM SPSS software (IBM SPSS Statistics Version 21.0; IBM Corporation, Armonk, NY, USA, 2014) and Review Manager software (RevMan Version 5.3; Cochrane collaboration, Oxford, UK, 2014). For continuous outcomes, we used mean differences with 95\% confidence intervals (CIs). We used standardized mean differences (SMDs) in cases combining unequal scales and units. The data were expressed as risk ratio (RR) or risk difference with $95 \%$ CI for dichotomous outcomes. For generic inverse variance outcomes, data were presented as odds ratio (OR) with 95\% CI.
For efficacy, this meta-analysis was performed on studies with the modified Jadad score $\geq 4$ and comparable clinical characteristics. The data from all included studies were analyzed for adverse events. Heterogeneity among studies was assessed with the $Q$ test and the $I$ index statistic. When statistical heterogeneity was not an issue $(P>0.1$ and $I^{2}$ statistics $\leq 50 \%$ ), a fixed-effects model was used. When moderate or high levels of heterogeneity $(P<0.1$ and $I^{2}$ statistics $>50 \%$ ) were detected, a random-effects model and a sensitivity analysis were performed to assess the robustness of the pooled outcomes. We attempted to do subgroup analysis using the different forms of preparation and formulas of CHM used in the experimental group.

\section{Results}

\section{Description of the paper selection process}

Our search yielded 6,927 potentially relevant articles for review. Of these, 4,213 were duplicates and 2,447 were excluded because of irrelevance. The remaining 267 articles were retrieved for detailed assessment. Of these, 249 were further excluded for various reasons (Figure 1). Finally, 18 studies were identified and analyzed for the number of adverse events and the use of CHM. Thirteen reports with moderate-to-high study quality (the modified Jadad score $\geq 4$ ) were selected for analysis of the efficacy of CHM.

\section{Quality assessment by the modified Jadad score}

\section{Assessment by Cochrane's risks of bias assessment}

The proportion and summary of the high, low, and unclear risk of bias of 18 studies, in which 13 studies with the modified Jadad scores $\geq 4$, are shown in Figures 2 and 3. Nine studies (studies 1, 2, 3, 4, 5, 6, 7, 10, and 13) were thought to have high risk of other bias. The subjects were diagnosed with a certain type of TCM syndrome differentiation by the clinician in these studies. The assessment of the subject's pulse condition and furred tongue relied on the clinician's own judgment and thus might have involved subjective bias. All studies mentioned blinding the participants and personnel. All studies mentioned that either all participants completed the trial or provided the number of dropouts. Study 5 provided the outcome data as International Prostate Symptom Score, but the data for outcome measures were not designed in advance.

\section{Reporting quality assessment by the CONSORT for TCM}

Based on the CONSORT for TCM, all the RCTs described the eligibility diagnostic criteria and both the inclusion and 


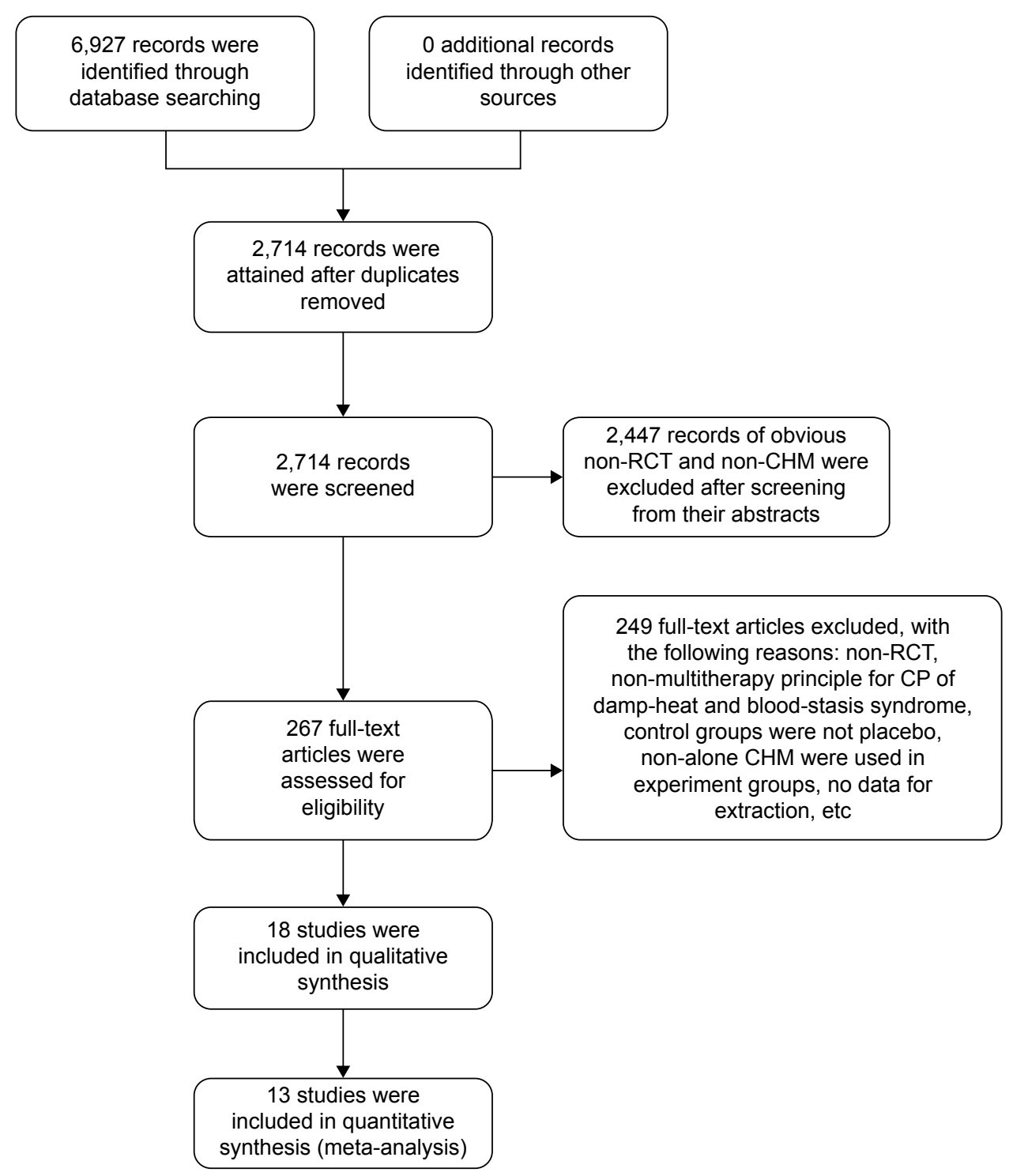

Figure I Study selection flow diagram for inclusion in the review.

Abbreviations: $\mathrm{CHM}$, Chinese herbal medicine; $\mathrm{CP}$, chronic prostatitis; $\mathrm{RCT}$, randomized controlled trial.

Random sequence generation (selection bias)

Allocation concealment (selection bias)

Blinding of participants and personnel (performance bias)

Blinding of outcome assessment (detection bias)

Incomplete outcome data (attrition bias)

Selective reporting (reporting bias)

Other bias

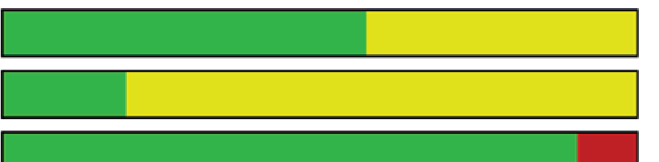

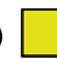

xcluded after screening

from their abstracts the following reasons: non-RCT, mp-heat and blood-stasis syndrome, , non-alone $\mathrm{CHM}$ were used in experiment groups, no data for xtraction, etc

(



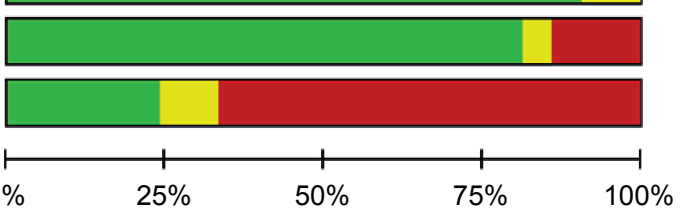

Low risk of bias

Unclear risk of bias

High risk of bias

Figure 2 Risk of bias graph. 


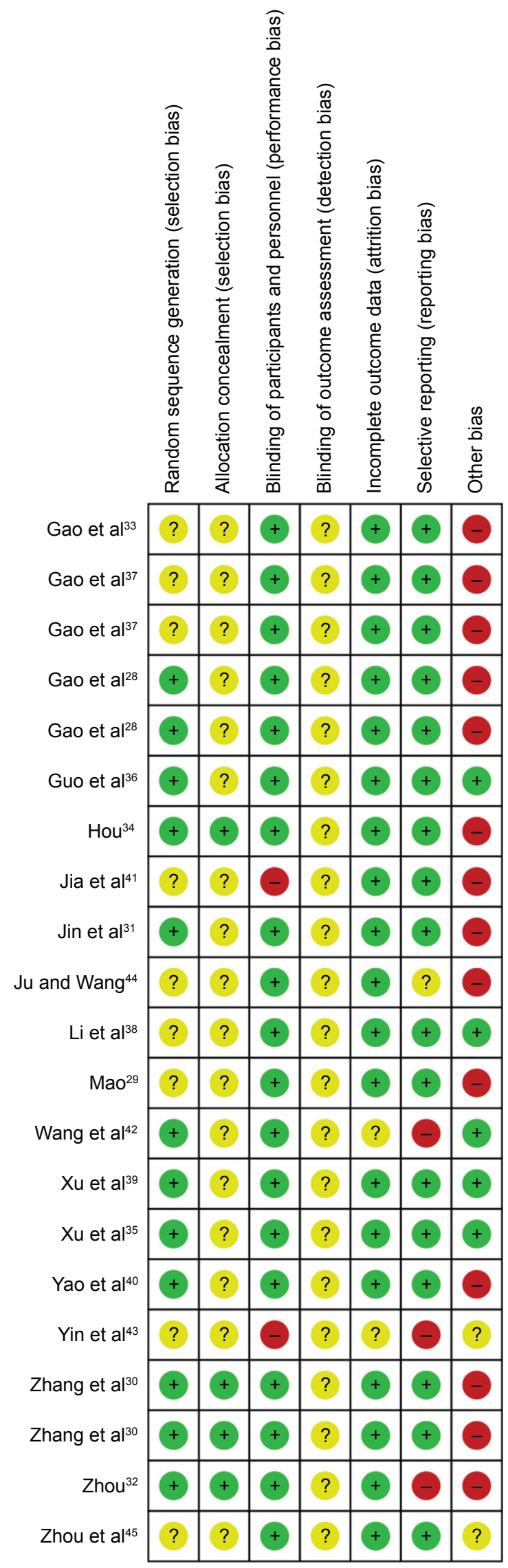

Figure 3 Risk of bias summary: review of authors' judgments about each risk of bias item for each included study. exclusion criteria of CP. Even though traditional Chinese formulas are commonly used based on syndrome differentiation, four studies failed to describe the TCM pattern diagnosis for CP in a particular TCM syndrome. Only study 2 did not report on patients' baseline demographics. All the RCTs documented the statistical methods used to compare outcomes between groups. All the RCTs either improperly reported or did not report multiple items, including specific objectives and hypothesis, clearly defined TCM symptoms, score outcomes, methods of random allocation concealment, ancillary analysis, generalizability, and precision of each outcome.

\section{Description of the studies}

Patient numbers of the 18 studies ranged from 20 to 336, comprising a total of 3,009 subjects. All the 13 moderateto-high-quality studies used placebo controls, were performed in the People's Republic of China, and were published in Chinese language journals between 2001 and 2014. Three studies adopted a three-arm study design (Table 1). The criteria used for diagnosis of $\mathrm{CP}$ associated with damp-heat and blood-stasis syndromes were reported in nine studies, including the clinical research guidelines of the new CHM and criteria of diagnosis and therapeutic effect of diseases and syndromes in TCM and Chinese internal medicine. All studies examined outpatients.

\section{Description of CHM used}

Nine Chinese herbal formulas (CHF) were examined in 18 studies. Huang Bo (Cortex Phellodendri), used in six (66.7\%) of the nine CHF, was the most frequently used single herb. The second most commonly reported herb was Ze Lan (Herba Lycopi) (44.4\%). This was followed by Da Huang (Rhubarb), Hu Zhang (Rhizoma Polygoni Cuspidati), and Chi Shao (Radix Paeoniae Rubra), each reported in $33.3 \%$ of the studies. Bai Jiang Cao (Herba Patriniae), Bi Xie (Sevenlobed Yam Rhizome), Zi Hua Di Ding (Herba Violae), Tao Ren (Semen Persicae), Jin Yin Hua (Flos lonicerae), Yi Yi Ren (Semen Coicis), Zhi Zi (Fructus Gardeniae), Pu Gong Ying (Herba Taraxaci), and Dan Shen (Radix Salviae Miltiorrhizae) were each reported in $22.2 \%$ of the studies. Seven (38.9\%) of the 18 studies administered CHF as suppositories; five $(27.8 \%)$ were manufactured in tablet form; three $(16.7 \%)$ in granules; and the remaining one $(0.6 \%)$ was in capsule form. The selected CHM was taken one to three times per day, and the treatment courses ranged from 4 weeks to 8 weeks.

\section{Efficacy assessment}

The 13 studies with the modified Jadad scores $\geq 4$ were selected for detailed assessment and meta-analysis. All 
Table I RCTs of CHM for CP associated with damp-heat and blood-stasis syndromes with modified jadad score $\geq 4$

\begin{tabular}{|c|c|c|c|c|c|c|}
\hline No & $\begin{array}{l}\text { First author } \\
\text { (year) }\end{array}$ & Country/type of case & $\begin{array}{l}\text { Ages, years } \\
\text { mean (range) }\end{array}$ & Diagnostic system & $\begin{array}{l}\text { TCM pattern } \\
\text { diagnosis }\end{array}$ & Design \\
\hline $\mathrm{I}$ & Gao $(2012)^{28}$ & China/outpatients with $\mathrm{CP}$ & $36.15(19-50)$ & CRG + USW & $\begin{array}{l}\text { Damp-heat and } \\
\text { blood-stasis } \\
\text { syndrome }\end{array}$ & $\begin{array}{l}\text { Three parallel arms } \\
\text { (low dose of CHM; high } \\
\text { dose of CHM; placebo) }\end{array}$ \\
\hline 2 & Mao $(2014)^{29}$ & China/outpatients with $\mathrm{CP}$ & $30.59(23-45)$ & CRG + USW & Heat stasis type & $\begin{array}{l}\text { Two parallel arms } \\
\text { (CHM; placebo) }\end{array}$ \\
\hline 3 & Zhang $(2014)^{30}$ & China/outpatients with CP & $34.84(18-50)$ & CRG & $\begin{array}{l}\text { Damp-heat and } \\
\text { blood-stasis } \\
\text { syndrome }\end{array}$ & $\begin{array}{l}\text { Three parallel arms } \\
\text { (low dose of } \mathrm{CHM} \text {; high } \\
\text { dose of } \mathrm{CHM} \text {; placebo) }\end{array}$ \\
\hline 4 & $\operatorname{Jin}(20 \mathrm{II})^{31}$ & China/outpatients with $\mathrm{CP}$ & NR (I8-50) & $\mathrm{HJS}+\mathrm{CDT}+\mathrm{CRG}$ & $\begin{array}{l}\text { Damp-heat and } \\
\text { stagnation syndrome }\end{array}$ & $\begin{array}{l}\text { Two parallel arms } \\
\text { (CHM; placebo) }\end{array}$ \\
\hline 5 & Zhou $(2002)^{32}$ & China/outpatients with $\mathrm{CP}$ & NR $(20-50)$ & CRG & $\begin{array}{l}\text { Damp-heat and } \\
\text { blood stasis }\end{array}$ & $\begin{array}{l}\text { Two parallel arms } \\
\text { (CHM; placebo) }\end{array}$ \\
\hline 6 & $\mathrm{Gao}(20 \mathrm{I0a})^{33}$ & China/outpatients with $\mathrm{CP}$ & $33(18-50)$ & CRG & $\begin{array}{l}\text { Type of damp-heat } \\
\text { and blood stasis }\end{array}$ & $\begin{array}{l}\text { Two parallel arms } \\
\text { (CHM; placebo) }\end{array}$ \\
\hline 7 & Hou $(20 \mathrm{II})^{34}$ & China/outpatients with $\mathrm{CP}$ & NR (I8-50) & CRG + USW & $\begin{array}{l}\text { Damp-heat mixed } \\
\text { blood }\end{array}$ & $\begin{array}{l}\text { Two parallel arms } \\
\text { (CHM; placebo) }\end{array}$ \\
\hline 8 & $\mathrm{Xu}(2005)^{35}$ & China/outpatients with $\mathrm{CP}$ & NR (20-55) & $\mathrm{NIH}-\mathrm{CPSI} \geq 4$ points & NR & $\begin{array}{l}\text { Two parallel arms } \\
\text { (CHM; placebo) }\end{array}$ \\
\hline 9 & Guo $(2007)^{36}$ & $\begin{array}{l}\text { China/outpatients with } \\
\text { CPPS by CP }\end{array}$ & $24.5(19-55)$ & USW & NR & $\begin{array}{l}\text { Two parallel arms } \\
\text { (CHM; placebo) }\end{array}$ \\
\hline 10 & $\mathrm{Gao}(2010 \mathrm{~b})^{37}$ & China/outpatients with CP & $33(18-50)$ & CRG & $\begin{array}{l}\text { Moist heat stagnant } \\
\text { blood stasis }\end{array}$ & $\begin{array}{l}\text { Three parallel arms } \\
\text { (CHM; placebo) }\end{array}$ \\
\hline 11 & $\operatorname{Li}(2003)^{38}$ & China/outpatients with $\mathrm{CP}$ & $32.7(20-50)$ & $\mathrm{NIH}-\mathrm{CPSI} \geq 10$ points & NR & $\begin{array}{l}\text { Two parallel arms } \\
\text { (CHM; placebo) }\end{array}$ \\
\hline 12 & $\mathrm{Xu}(2002)^{39}$ & China/outpatients with $\mathrm{CP}$ & NR (20-55) & $\mathrm{NIH}-\mathrm{CPSI} \geq 10$ points & NR & $\begin{array}{l}\text { Two parallel arms } \\
\text { (CHM; placebo) }\end{array}$ \\
\hline 13 & Yao $(2008)^{40}$ & China/outpatients with $\mathrm{CP}$ & $30.1(20-55)$ & $\begin{array}{l}\mathrm{NIH}-\mathrm{CPSI} \geq 10 \text { points }+ \\
\mathrm{CIM}+\mathrm{SC}\end{array}$ & $\begin{array}{l}\text { Damp-heat } \\
\text { stagnation }\end{array}$ & $\begin{array}{l}\text { Two parallel arms } \\
\text { (CHM; placebo) }\end{array}$ \\
\hline
\end{tabular}

Notes: Qianlie Xiaoyan Zhitong tablet and Qianliean tablet with the same formula and different names were handled within subgroup analysis. In the case of three numbers, the first two are different treatment group, the third is control group.

Abbreviations: CHM, Chinese herbal medicine; CIM, Chinese internal medicine; CPPA, chronic pelvic pain syndrome; CP, chronic prostatitis; HJS, Huang Jiasi surgery; IPSS, International Prostate Symptom Score; NIH-CPSI, National Institutes of Health chronic prostatitis symptom index; NR, not reported; SC, surgery of Chinese; WBC, white blood cell; bid, twice daily; CDT, criteria of diagnosis and therapeutic effect of diseases and syndromes in traditional Chinese medicine; CRG, clinical research guidelines of new CHM; USW, urological surgery written by Wu Jie-Ping; RCTs, randomized controlled trials.

studies reported the effective rate. CHM was reported to be more effective than placebo (OR: $6.72,95 \% \mathrm{CI}$ : 2.78-9.48, $P<0.00001)$. Additionally, there were significant differences between CHM and placebo in improving the symptoms score (NIH-CPSI and SI-CM) (SMD: -1.06 , 95\% CI: -1.46 to $-0.65, P<0.00001$ and SMD: -1.08 , 95\% CI: -1.35 to $-0.81, P<0.00001)$ except in the case of Prostant (NIH-CPSI) (SMD: $-0.23,95 \%$ CI: -0.46 to 0.01 , $P=0.06$ ), further confirming its positive therapeutic effect (Figures 4-6). Oral CHMs were significantly more effective than placebo in terms of reduction of NIH-CPSI scores with a mean difference of -1.39 (95\% CI: -1.87 to -0.92 , $P<0.00001)$. However, no significant differences were found between Prostant and placebo (SMD: $-0.23,95 \%$ CI: -0.46 to $0.01, P=0.06$ ).

\section{Safety assessment}

Adverse events were shown in 15 of the 18 reviewed studies. Of the three excluded studies, two failed to provide the frequency of placebo-related adverse events because of different forms of preparation (ie, suppository versus oral); the third excluded study included a randomized self-crossover control trial. Meta-analysis of the ten studies that compared oral CHM with placebo demonstrated that there were no significant differences between groups in the occurrence of adverse events (RR: $1.36,95 \% \mathrm{CI}$ : $0.72-2.55, I^{2}=0 \%, P=0.34$ ) (Figure 7). A pooled analysis of five studies comparing Prostant with placebo showed that Prostant was associated with a higher frequency of adverse events (RR: $1.63,95 \%$ CI: $1.14-2.34, I^{2}=0 \%$, $P=0.008$ ) (Figure 8 ). 


\begin{tabular}{|c|c|c|c|c|c|c|}
\hline Follow-up & $\begin{array}{l}\text { Sample size } \\
\text { (CHM/control) }\end{array}$ & $\begin{array}{l}\text { Treatment intervention } \\
\text { (duration) }\end{array}$ & $\begin{array}{l}\text { Control } \\
\text { intervention }\end{array}$ & Outcome measure & Results reported & $\begin{array}{l}\text { Modified } \\
\text { Jadad score }\end{array}$ \\
\hline Nil & $206(68 / 68 / 70)$ & $\begin{array}{l}\text { Longbi Xintong granule } 8 \mathrm{~g} \text {, } \\
\text { qd/8 g, bid (4 weeks) }\end{array}$ & Placebo & $\begin{array}{l}\text { NIH-CPSI, effective } \\
\text { rate, SI-CM, EPS-WBC }\end{array}$ & $\begin{array}{l}\text { CHM significantly }> \\
\text { placebo }\end{array}$ & 5 \\
\hline Nil & $74(54 / 20)$ & $\begin{array}{l}\text { Longbi Xintong granule } 8 \mathrm{~g} \text {, } \\
\text { bid ( } 4 \text { weeks) }\end{array}$ & Placebo & $\begin{array}{l}\mathrm{NIH}-\mathrm{CPSI} \text {, effective } \\
\text { rate, SI-CM, EPS }\end{array}$ & $\begin{array}{l}\text { CHM significantly > } \\
\text { placebo }\end{array}$ & 4 \\
\hline Nil & $254(86 / 83 / 85)$ & $\begin{array}{l}\text { Compound Huangkui granule } \\
9 \mathrm{~g} / 12 \mathrm{~g} \text {, tid ( } 8 \text { weeks) }\end{array}$ & Placebo & $\begin{array}{l}\text { NIH-CPSI, effective } \\
\text { rate, SI-CM }\end{array}$ & $\begin{array}{l}\text { CHM significantly }> \\
\text { placebo }\end{array}$ & 7 \\
\hline 4 weeks & $225(113 / 112)$ & $\begin{array}{l}\text { Qianlie Xiaoyan Zhitong } \\
\text { tablet } 1.48 \text { g, tid ( } 28 \text { days) }\end{array}$ & Placebo & $\begin{array}{l}\mathrm{NIH}-\mathrm{CPSI} \text {, effective } \\
\text { rate, SI-CM, EPS }\end{array}$ & $\begin{array}{l}\text { CHM significantly > } \\
\text { placebo }\end{array}$ & 5 \\
\hline Nil & $62(32 / 30)$ & $\begin{array}{l}\text { Qianliean tablet } 7 \mathrm{~g} \text {, tid } \\
(4 \text { weeks })\end{array}$ & Placebo & $\begin{array}{l}\mathrm{NIH}-\mathrm{CPSI} \text {, effective } \\
\text { rate, SI-CM, EPS }\end{array}$ & $\begin{array}{l}\text { CHM significantly > } \\
\text { placebo }\end{array}$ & 7 \\
\hline Nil & $442(336 / 106)$ & $\begin{array}{l}\text { Longqing tablet } 3.6 \mathrm{~g} \text {, bid } \\
\text { (4 weeks) }\end{array}$ & Placebo & $\begin{array}{l}\mathrm{NIH}-\mathrm{CPSI} \text {, effective } \\
\text { rate, SI-CM, EPS }\end{array}$ & $\begin{array}{l}\text { CHM significantly > } \\
\text { placebo }\end{array}$ & 4 \\
\hline Nil & $74(38 / 36)$ & $\begin{array}{l}\text { Amber capsule } 1.76 \mathrm{~g} \text {, bid } \\
(4 \text { weeks) }\end{array}$ & Placebo & $\begin{array}{l}\mathrm{NIH}-\mathrm{CPSI} \text {, effective } \\
\text { rate, SI-CM, EPS }\end{array}$ & $\begin{array}{l}\text { CHM significantly > } \\
\text { placebo }\end{array}$ & 7 \\
\hline Nil & II $6(59 / 57)$ & $\begin{array}{l}\text { Wenglitong tablet } 1.2 \mathrm{~g} \text {, bid } \\
\text { (4 weeks) }\end{array}$ & Placebo & $\begin{array}{l}\mathrm{NIH}-\mathrm{CPSI} \text {, effective } \\
\text { rate }\end{array}$ & $\begin{array}{l}\text { CHM significantly > } \\
\text { placebo }\end{array}$ & 5 \\
\hline Nil & $197(99 / 98)$ & $\begin{array}{l}\text { Qianlie Antong tablet } 1.9 \mathrm{~g} \text {, } \\
\text { tid (4 weeks) }\end{array}$ & Placebo & $\begin{array}{l}\text { NIH-CPSI, effective } \\
\text { rate, EPS-WBC }\end{array}$ & $\begin{array}{l}\text { CHM significantly }> \\
\text { placebo }\end{array}$ & 5 \\
\hline Nil & $229(58 / 1$ I $3 / 58)$ & $\begin{array}{l}\text { Prostant } 2 \mathrm{~g} / \text { Qianlie Miniao } \\
\text { Shuan } 2.5 \mathrm{~g} \text { qn ( } 4 \text { weeks) }\end{array}$ & Placebo & $\begin{array}{l}\mathrm{NIH}-\mathrm{CPSI} \text {, effective } \\
\text { rate, } \mathrm{SI}-\mathrm{CM}\end{array}$ & $\begin{array}{l}\text { CHM significantly }> \\
\text { placebo }\end{array}$ & 4 \\
\hline Nil & $124(64 / 60)$ & Prostant $2 \mathrm{~g}$, qn (I month) & Placebo & $\begin{array}{l}\text { NIH-CPSI, effective } \\
\text { rate, EPS-WBC }\end{array}$ & $\begin{array}{l}\text { CHM significantly }> \\
\text { placebo }\end{array}$ & 4 \\
\hline Nil & $70(35 / 35)$ & Prostant 2 g, qn (I month) & Placebo & $\begin{array}{l}\text { NIH-CPSI, effective } \\
\text { rate, EPS-WBC }\end{array}$ & $\begin{array}{l}\text { CHM significantly }> \\
\text { placebo }\end{array}$ & 5 \\
\hline Nil & $40(20 / 20)$ & Prostant $2 \mathrm{~g}$, qn (4 weeks) & Placebo & $\begin{array}{l}\text { NIH-CPSI, effective } \\
\text { rate, EPS-WBC }\end{array}$ & $\begin{array}{l}\text { CHM significantly }> \\
\text { placebo }\end{array}$ & 4 \\
\hline
\end{tabular}

A summary of all reported adverse events is given in Table 2. Only anal discomfort (RR: 1.63, 95\% CI: 1.06-2.49, four studies, $P=0 \%, P=0.03$ ) was found to be more frequent in patients taking Prostant than those taking placebo regarding individual events. The frequencies of the adverse events from the nine studies that compared CHM with placebo showed no significant differences.

\section{Discussion}

This is the first systematic review to investigate the efficacy and safety of CHM for the treatment of $\mathrm{CP}$ associated with damp-heat and blood-stasis syndromes. There are different therapeutic interventions for $\mathrm{CP}$, including a-Blocker, antibiotic, anti-inflammatory drugs. Compared to those, one advantage of CHMs therapeutics is the CHF, that is, multiple components in CHF often play a synergistic role that is greater than that of the individual drug. In the meantime, the "one disease, one target, one drug" mode cannot treat some complex diseases effectively, such as CP. Here, we examined the frequency of the most commonly used herbs for the treatment of this disease. Our findings from 18 RCTs suggested that CHM was superior to placebo for $\mathrm{CP}$ associated with damp-heat and bloodstasis syndromes. Additionally, the meta-analyses of the moderate-to-high-quality studies provide evidence for this conclusion. However, owing to an insignificant improvement in NIH-CPSI score for $\mathrm{CP}$, a statistically significant difference $(P=0.06)$ in NIH-CPSI score was not found in the Prostant group compared to the placebo group in our meta-analysis. 


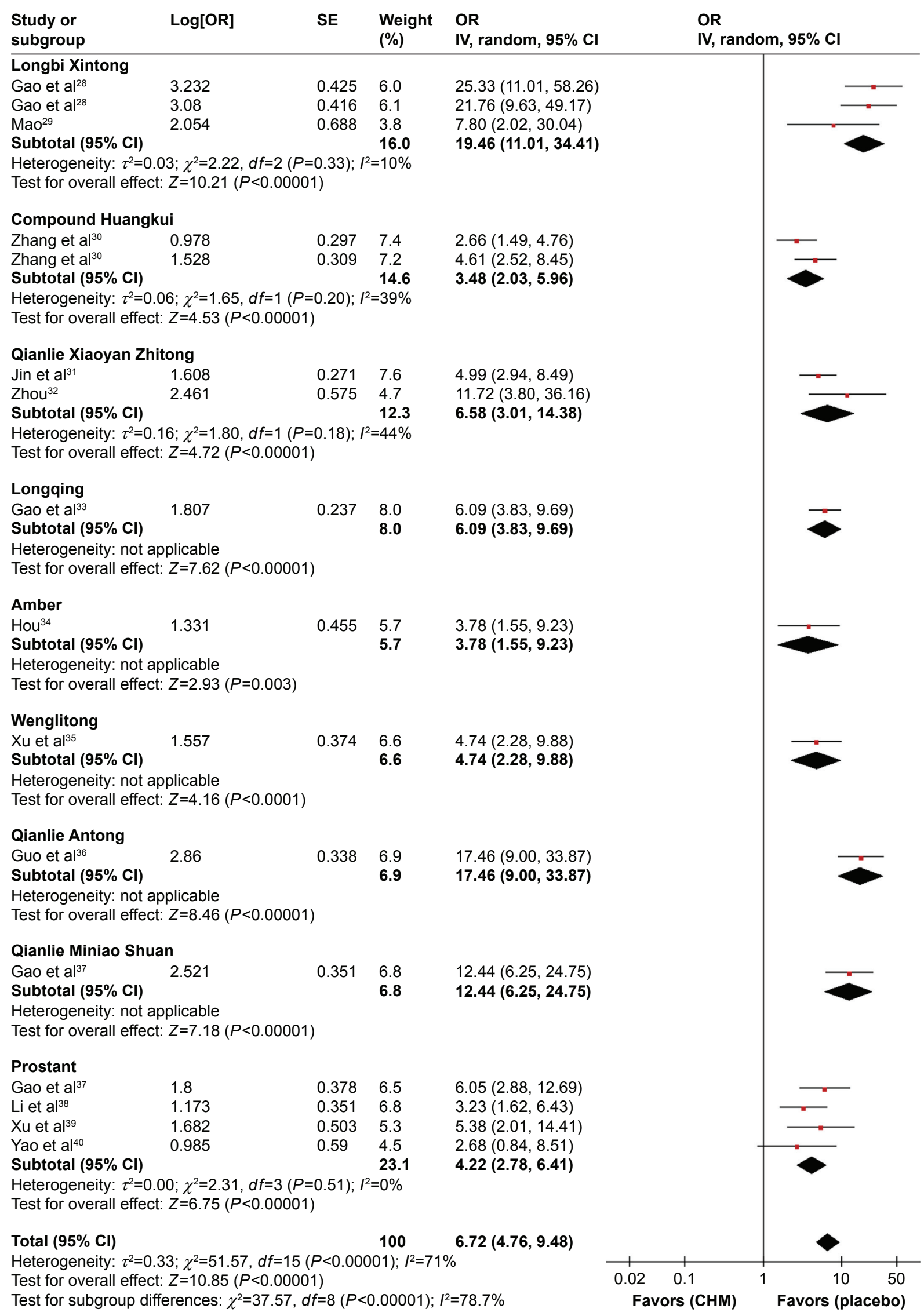

Figure 4 Efficacy rate when using $\mathrm{CHM}$ and placebo for $\mathrm{CP}$ associated with damp-heat and blood-stasis syndromes.

Abbreviations: $\mathrm{CHM}$, Chinese herbal medicine; $\mathrm{Cl}$, confidence interval; $\mathrm{CP}$, chronic prostatitis; SE, standard error; OR, odds ratio. 


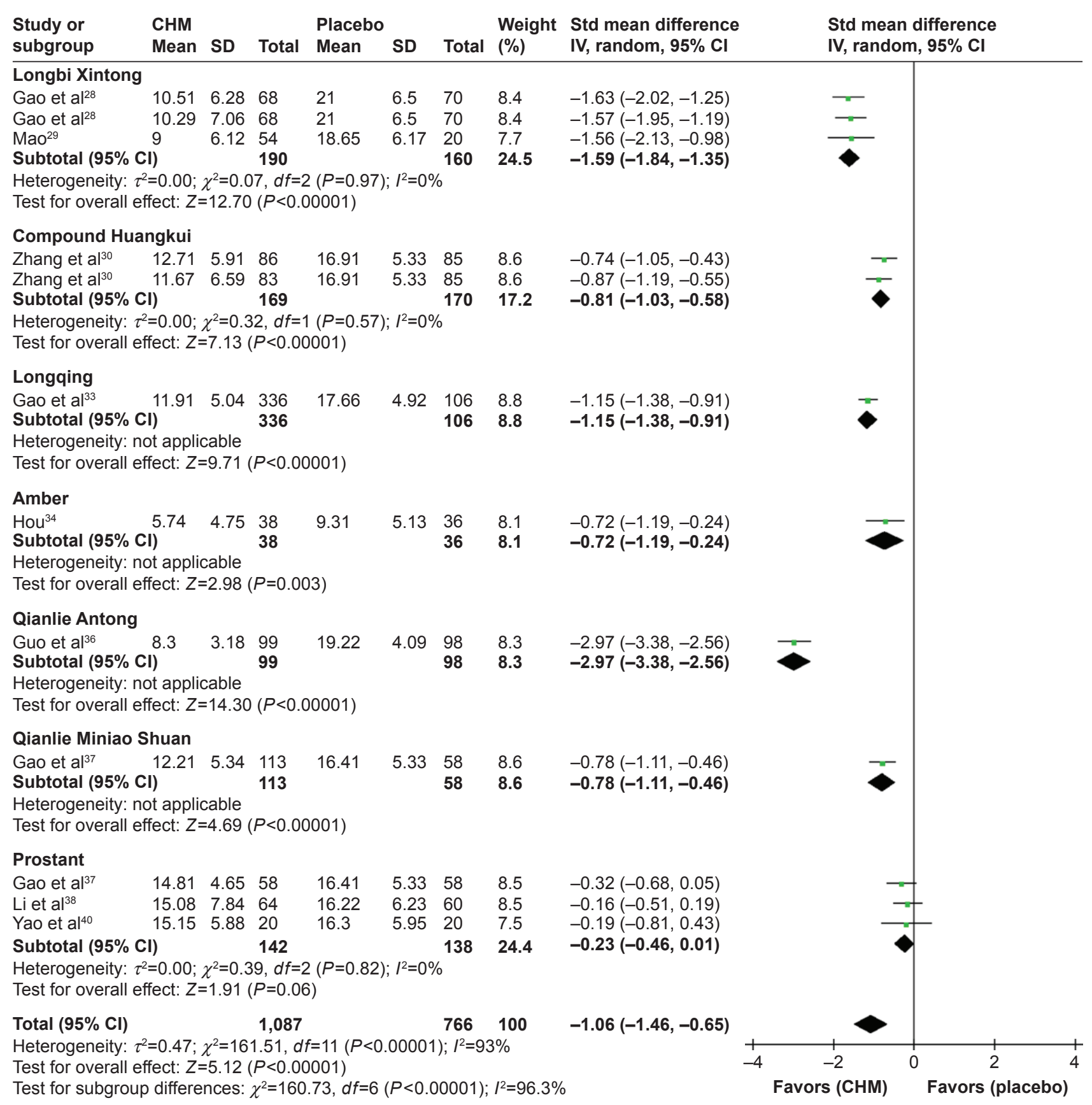

Figure $5 \mathrm{NIH}$-CPSI score when using CHM and placebo for $\mathrm{CP}$ associated with damp-heat and blood-stasis syndromes.

Abbreviations: CHM, Chinese herbal medicine; $\mathrm{Cl}$, confidence interval; CP, chronic prostatitis; $\mathrm{NIH}$-CPSI, National Institutes of Health chronic prostatitis symptom index; Std, standard; SD, standard deviation.

The use of CHM as monotherapy was diversified in the formula composition and dosage of the included studies. Based on the signs and symptoms of individual patients, TCM practitioners would classify them into different syndrome differentiations (Zheng in Chinese) and prescribe herbal formulas accordingly. ${ }^{15}$ Therefore, even trials with exact CHM formulas and dosages may not simulate the usual practice of TCM, thus rendering proving the efficacy of a particular formula impossible.
From the point of view of TCM, CP belongs to "Turbid Semen", "Stranguria", and "Gonorrhea". ${ }^{4}$ TCM theory also states that there are four kinds of general syndromes, including downward flow of damp-heat, blood stasis due to qi stagnation, stagnation of liver-qi, and deficiency of kidney-yang, which influence treatment options. There are also two kinds of compound syndromes - one is damp-heat and blood stasis and the other is liver-kidney yin deficiency. TCM believes that the damp-heat and blood-stasis syndrome 


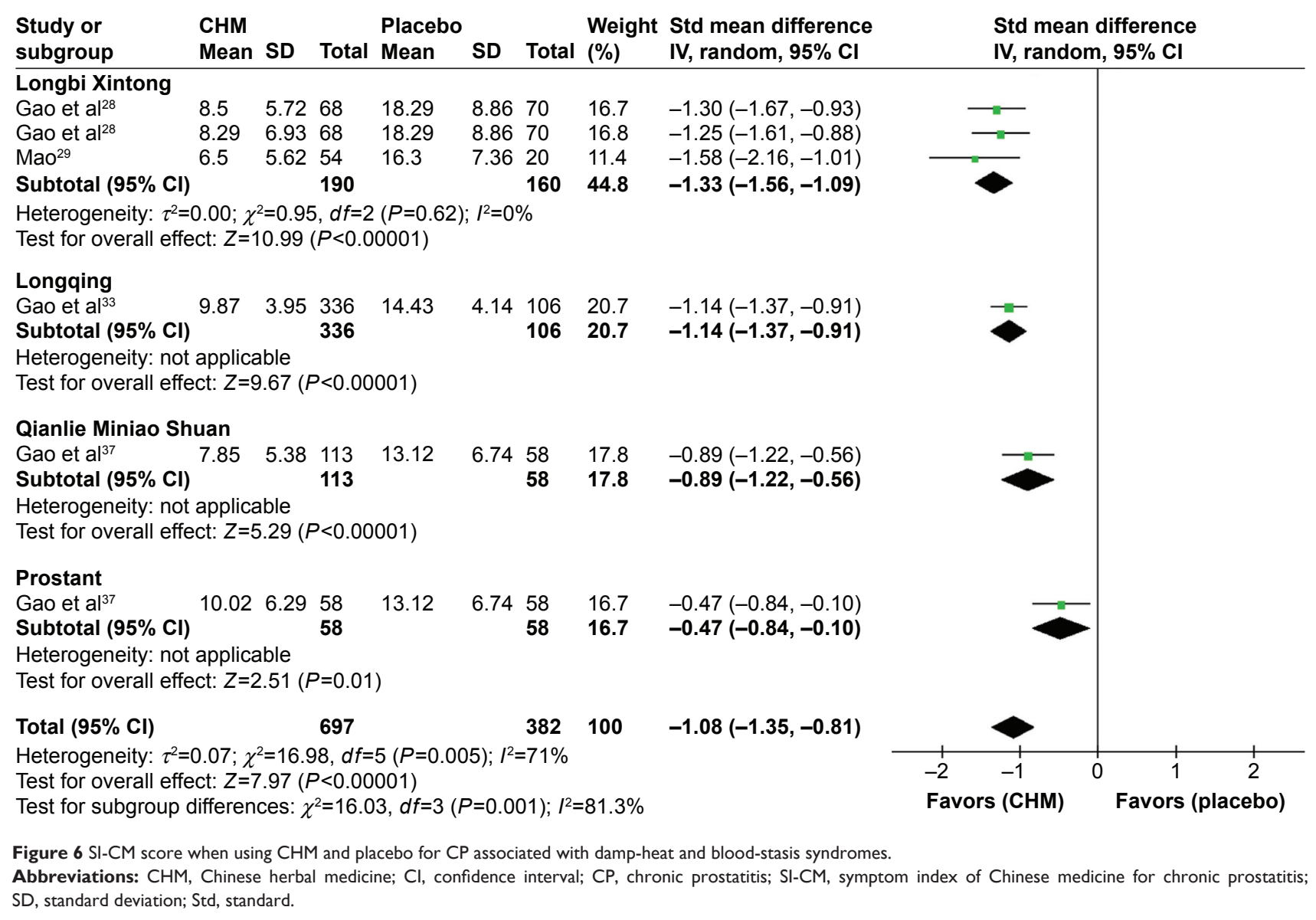

is the most common compound syndrome differentiation of Turbid Semen, Stranguria, and Gonorrhea. ${ }^{16}$ Syndrome differentiation and treatment in CHM can get significant improvement in clinical symptoms of four different CP categories by the National Institute of Health. ${ }^{17,18}$ Thus, reducing the damp-heat and removing the blood stasis are considered to be the major strategies to treat Turbid Semen, Stranguria, and Gonorrhea.

Among the nine CHF reported in the 18 included studies, Cortex Phellodendri ( $n=6)$ was the most frequently used herb, likely because it is considered to clear away damp-heat in the lower energizer by TCM practitioners. Herba Lycopi $(n=4)$, a strong blood stasis-removing herb, was the second most commonly used CHF. Rhubarb, Rhizoma Polygoni Cuspidati, and Radix Paeoniae Rubra (n=3) were the third most frequently used herbs. These herbs are considered to be blood circulation enhancers and damp-heat cleaners. TCM believes that CP associated with damp-heat and blood-stasis syndrome is mainly caused by pathogenic damp-heat and blood stasis, which blocks the lower energizer. Thus, this CP is frequently treated through clearing away the damp-heat in the lower energizer and promoting blood circulation to prevent blood stasis.

Some pharmacological studies have provided scientific evidence to use herbs to treat CP. Berberine, for example, the major ingredient of the Cortex Phellodendri, has been described as an anti-inflammatory, ${ }^{19}$ has antimicrobial properties, ${ }^{20,21}$ and inhibits the $\alpha 1$ receptor. ${ }^{22}$ Berberine may also significantly reduce the synthesis of prostaglandins and other chemical mediators from arachidonic acid by inhibiting cyclooxygenase- 2 transcriptional activity. The antimicrobial properties of Berberine have also been demonstrated via inhibition of DNA synthesis and reverse transcriptase in Escherichia coli and Staphylococcus aureus. Herba Lycopi ${ }^{23}$ was found to improve hematological rheology. Emodin, an active ingredient of Rhubarb and Rhizoma Polygoni Cuspidati, was found to possess anti-inflammatory, anticarcinogenic, antibacterial, and antiviral properties; it was also shown to inhibit platelet aggregation. ${ }^{24,25}$ Radix Paeoniae Rubra ${ }^{26}$ was found to possess anti-inflammatory and acesodyne effects.

Adverse events occurred at similar incidence rates among patients receiving $\mathrm{CHM}$ or placebo. The one exception was 
Study or subgroup
Longbi Xintong

Gao et al ${ }^{28}$

$\mathrm{MaO}^{29}$

Subtotal $(95 \% \mathrm{Cl})$

Total events 3

Heterogeneity: $\tau^{2}=0.00 ; \chi^{2}=0.45, d f=1(P=0.50) ; I^{2}=0 \%$

Test for overall effect: $Z=0.17(P=0.87)$

\section{Qianlie Xiaoyan Zhitong}

\begin{tabular}{lllllll} 
Jin et al & & & & & \\
Zhou $^{32}$ & 5 & 113 & 4 & 112 & 10.3 & $1.24(0.34,4.49)$ \\
Subtotal (95\% CI) & 1 & 32 & 0 & 30 & 2.3 & $2.82(0.12,66.62)$ \\
Total events & 6 & $\mathbf{1 4 5}$ & & $\mathbf{1 4 2}$ & $\mathbf{1 2 . 7}$ & $\mathbf{1 . 3 9}(\mathbf{0 . 4 2}, \mathbf{4 . 5 9 )}$ \\
\hline
\end{tabular}

Heterogeneity: $\tau^{2}=0.00 ; \chi^{2}=0.22, d f=1 \quad(P=0.64) ; I^{2}=0 \%$

Test for overall effect: $Z=0.54(P=0.59)$

\section{Wenglitong}

Xu et $\mathrm{al}^{35}$

Zhou $^{32}$

Subtotal $(95 \% \mathrm{CI})$

Total events

$5 \quad 59 \quad 1$

$11 \quad 52$

16

111

$\begin{array}{ll}57 & 4.8 \\ 48 & 17.2 \\ \mathbf{1 0 5} & \mathbf{2 2 . 0}\end{array}$

$4.83(0.58,40.08)$

$1.27(0.56,2.89)$

Heterogeneity: $\tau^{2}=0.26 ; \chi^{2}=1.39, d f=1(P=0.24) ; I^{2}=28 \%$

Test for overall effect: $Z=0.95(P=0.34)$

\section{Longqing}

Gao et al ${ }^{33}$

Subtotal $(95 \% \mathrm{Cl})$

Total events

359
359

359

$120 \quad 10.8$

Heterogeneity: not applicable

Test for overall effect: $Z=0.46(P=0.65)$

Prostant

\begin{tabular}{|c|c|c|}
\hline Gao et $\mathrm{al}^{37}$ & 1 & 58 \\
\hline Jia et $\mathrm{al}^{41}$ & 44 & 310 \\
\hline Li et $\mathrm{al}^{38}$ & 2 & 64 \\
\hline Wang et $\mathrm{al}^{42}$ & 30 & 70 \\
\hline Xu et $a^{39}$ & 1 & 35 \\
\hline Yao et $\mathrm{al}^{40}$ & 4 & 20 \\
\hline Yin et $\mathrm{al}^{43}$ & 33 & 120 \\
\hline Subtotal (95 & & 677 \\
\hline
\end{tabular}

Total events 115

23

$\begin{array}{lll}58 & 2.3 & 3.00(0.12,72.15) \\ 100 & 3.0 & 28.90(1.80,465.10) \\ 60 & 2.6 & 4.69(0.23,95.79) \\ 70 & 25.2 & 1.50(0.95,2.37) \\ 35 & 2.3 & 3.00(0.13,71.22) \\ 20 & 9.6 & 1.33(0.34,5.21) \\ 60 & 3.0 & 33.78(2.11,541.95) \\ \mathbf{4 0 3} & \mathbf{4 8 . 0} & \mathbf{3 . 8 5}(\mathbf{1 . 0 9}, \mathbf{1 3 . 5 7})\end{array}$

RR

$\mathrm{M}-\mathrm{H}$, random, $95 \% \mathrm{Cl}$

Heterogeneity: $\tau^{2}=1.55 ; \chi^{2}=17.54, d f=6(P=0.007) ; I^{2}=66 \%$

Test for overall effect: $Z=2.09(P=0.04)$

$\begin{array}{lllll}\text { Total }(95 \% \mathrm{Cl}) & 1,414 & 860 & 100 & 1.84(1.11,3.05)\end{array}$

$\begin{array}{lcc}\text { Total events } \quad 152 & 41 \\ \text { Heterogeneity: } \tau^{2}=0.21 ; \chi^{2}=18.07, d f=13(P=0.15) ; I^{2}=28 \%\end{array}$

Test for overall effect: $Z=2.38(P=0.02)$

Test for subgroup differences: $\chi^{2}=2.38, d f=4(P=0.67) ; I^{2}=0 \%$

$1.74(0.56,5.38)$

$1.34(0.38,4.66)$

$0.51(0.05,5.55)$

$0.85(0.13,5.50)$

$1.34(0.38,4.66)$

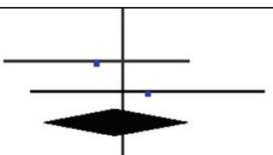

igure 7 Likelihood of adverse events when using oral $\mathrm{CHM}$ and placebo.

Abbreviations: $\mathrm{CHM}$, Chinese herbal medicine; $\mathrm{Cl}$, confidence interval; $\mathrm{M}-\mathrm{H}$, Mantel-Haenszel method; RR, risk ratio.

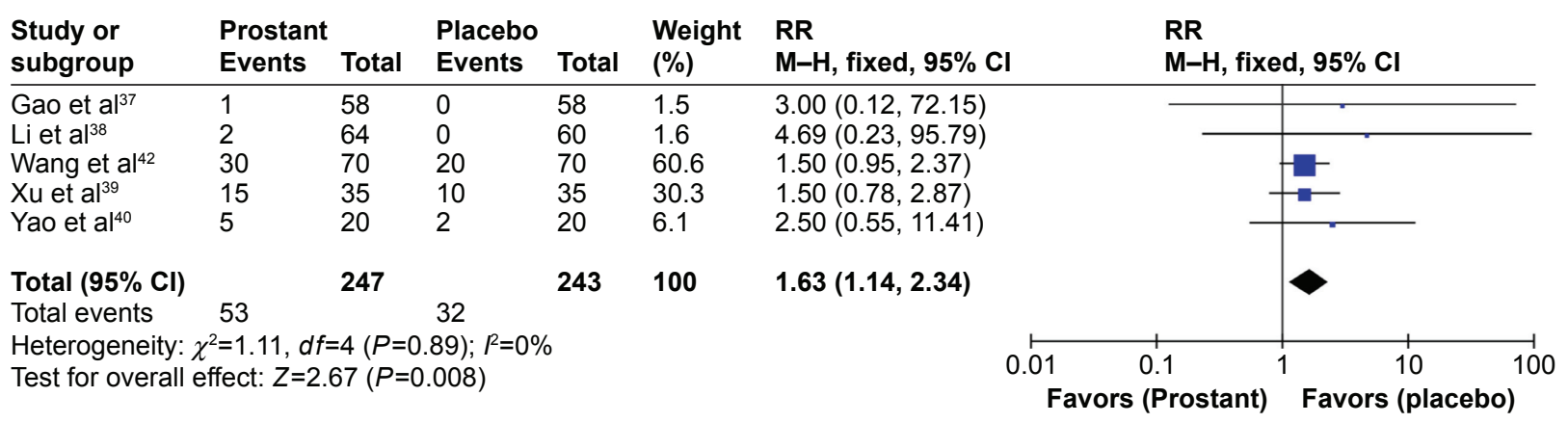

Figure 8 Likelihood of adverse events when using Prostant and placebo.

Abbreviations: $\mathrm{Cl}$, confidence interval; $\mathrm{M}-\mathrm{H}$, Mantel-Haenszel method; RR, risk ratio. 
Table 2 RR of all reported adverse events in studies comparing CHM with placebo

\begin{tabular}{|c|c|c|c|c|c|}
\hline \multirow[t]{2}{*}{ Adverse event } & \multicolumn{2}{|c|}{ Total event/group total } & \multirow[t]{2}{*}{ RR (95\% Cl) } & \multirow{2}{*}{$\begin{array}{l}\text { No of } \\
\text { studies }\end{array}$} & \multirow{2}{*}{$\begin{array}{l}\text { Heterogeneity } \\
\left(I^{2}\right) \%\end{array}$} \\
\hline & $\mathrm{CHM}$ & Placebo & & & \\
\hline & Oral CHM & Placebo & & & \\
\hline Stomach upset & $7 / 680$ & $5 / 407$ & $0.80(0.27-2.39)$ & 5 & 0.0 \\
\hline Nausea & $2 / 518$ & $2 / 227$ & $0.75(0.18-3.18)$ & 4 & 0.0 \\
\hline Mild stomachache & $1 / 86$ & $\mathrm{I} / 85$ & $0.99(0.06-15.55)$ & 1 & NA \\
\hline Mild abdominal distention & $3 / 145$ & $1 / 142$ & $2.28(0.34-15.30)$ & 2 & 0.0 \\
\hline Mild diarrhea & $6 / 185$ & $5 / 180$ & I. I5 (0.4I-3.27) & 3 & 0.0 \\
\hline Severe diarrhea & $1 / 36$ & $1 / 36$ & $3.00(0.13-7 \mid .28)$ & I & NA \\
\hline Urticaria & $1 / 113$ & $0 / 112$ & $2.97(0.12-72.23)$ & 1 & NA \\
\hline Cold/sore throat & $3 / 113$ & $2 / 112$ & $1.49(0.25-8.73)$ & 1 & NA \\
\hline Abnormal liver function & $0 / 113$ & $2 / 112$ & $0.20(0.01-4.08)$ & I & NA \\
\hline \multirow[t]{2}{*}{ Pruritus } & $1 / 59$ & $0 / 57$ & $2.90(0.12-69.75)$ & I & NA \\
\hline & Prostant & Placebo & & & \\
\hline Anal discomfort & $41 / 183$ & $25 / 183$ & $1.63(1.06-2.49)$ & 4 & 0.0 \\
\hline Archorrhagia & $1 / 64$ & $0 / 64$ & $3.00(0.12-72.29)$ & I & NA \\
\hline Loose stool & $3 / 20$ & $1 / 20$ & $3.00(0.34-26.45)$ & I & NA \\
\hline
\end{tabular}

Abbreviations: $\mathrm{CHM}$, Chinese herbal medicine; $\mathrm{Cl}$, confidence interval; NA, not applicable; RR, risk ratio.

anal discomfort, which occurred more frequently in the Prostant group compared to the placebo group. These side effects are known to occur in a small proportion of patients receiving Prostant. In order to improve patient adherence, we should give correct instructions and explanations to patients, especially concerning the treatment duration needed before assessing symptomatic relief, to avoid unrealistic expectations. Thus, we recommend that when one considers Prostant treatment, attention should be paid to monitoring for symptoms of anal discomfort. However, it should also be noted that symptoms of anal discomfort disappeared within 1-2 weeks after the start of treatment.

\section{Limitations}

Before accepting the abovementioned positive findings, the following limitations should also be considered. First, Vickers et $\mathrm{al}^{26}$ pointed out that only positive results were produced in some countries. In our review, all the 13 included studies were conducted in the People's Republic of China and published in Chinese. Moreover, positive results were reported in most of the included studies, and some negative results could not be reported. We understand that negative results are often difficult to be accepted in most Chinese journals currently. Thus, the efficacy of CHM for CP associated with damp-heat and blood-stasis syndromes might be overestimated. Similar questions were also confronted in the previously published systematic reviews of CHM. ${ }^{26}$

Second, we rigorously assessed the methodologic quality of the included trials based on the modified Jadad scores, Cochrane Collaboration's tool, and CONSORT for TCM. To set a minimum standard for the paper's results to be included in a meta-analysis, a researcher conducting a systematic review, for example, might elect to exclude all papers on the topic with a Jadad score of 3 or less. ${ }^{27}$ The methodologic quality is poor, which is the inherent shortcomings in primary studies. For example, all the included studies declared that participants were randomized into the CHM group and placebo group; however, only nine described the method of generation sequence, and allocation concealment was only used in three of the nine trials. The assessment of subjects' pulse condition and furred tongue relied on the clinicians' own judgment and thus might weaken the strength and credibility of the clinical evidence of CHM in this review.

Third, patients are not administered the same CHM for a long period of time in real practice, and the treatments reported in clinical trials did not follow a pattern that is commonly used in actual clinical practice because syndrome is dynamic during the treatment course. The diversity of CHM reported in our studies made the results difficult to be directly applied to clinical practice. Therefore, we only presented the most frequently used herbs that might provide various beneficial effects. ${ }^{24}$ We should consider and apply them in their clinical settings and researches, respectively.

\section{Conclusion}

CHM is not associated with increased adverse events or discontinuations compared with placebo. The novel data we present here demonstrate that CHM ranks the highest in terms of improvement of $\mathrm{CP}$ associated with damp-heat and blood-stasis syndrome. Prostant was also effective at treating this type of disorder, although it was associated with a smaller reduction in NIH-CPSI score. More importantly, 
the monotherapy of CHM was safe. In conclusion, this meta-analysis of 13 RCTs comparing CHM and placebo shows that CHM can be used safely and effectively for the treatment of CP associated with damp-heat and blood-stasis syndrome. This study is a meta-analysis of published data. A large, double-blind, RCT is required to prove the outcomes of this meta-analysis because the number of patients enrolled in the trials is limited.

\section{Acknowledgment}

This study is supported by the Shouguang Hospital of Traditional Chinese Medicine.

\section{Disclosure}

The authors report no conflicts of interest in this work.

\section{References}

1. Liang CZ, Li HJ, Wang ZP, et al. Treatment of chronic prostatitis in Chinese men. Asian J Androl. 2009;11(2):153-156.

2. Zhou ZX, Yu PL, Dong BR, Jian ZJ. Current status of diagnosis and treatment for benign prostatic hyperplasia in geriatrics outpatient. Chin J Geriatr. 2011;30:965-967.

3. Jiang M, Zhang C, Zheng G, et al. Traditional Chinese medicine Zheng in the era of evidence-based medicine: a literature analysis. Evid Based Complement Alternat Med. 2012;2012:409568.

4. Medicine. APcoCITaW. Expert consensus of integrated traditional and western medicine in the diagnosis and treatment of chronic prostatitis. Chin J Integrat Tradit Chin West Med. 2015;35:933-941.

5. Li LQ, Wang CH, Liu CY, et al. Frequency on distribution of TCM syndromes with chronic prostatitis. Chin J Tradit Chin Med Pharm. 2005;20:245-246.

6. Zhou Q, He JQ, Wang DJ, et al. Investigation on distribution of TCM syndromes in 1083 patients with chronic prostatitis. JTCM Uinv Hunan. 2008;28:71-79.

7. Zhang MJ, Weng JF, Shi YL, Cheng WJ, Ruan XJ, Zhang QY. Effect of aike mixture on the inflammatory infiltration in patients with chronic prostatitis type III A. Chin J Integr Med. 2011;17(1):26-30.

8. Chang DG, Wang TQ, Wei YJ, Zhang PH, Qu XW, Wu TL. [Modified Bazhengsan for urination symptoms of chronic prostatis with damp-heat accumulated in the lower jiao]. Zhonghua nan kexue/NatlJ Androl.2010; 16:664-668. Chinese.

9. Chen KJ. Blood stasis syndrome and its treatment with activating blood circulation to remove blood stasis therapy. Chin J Integr Med. 2012; 18:891-896.

10. Chen JX, Hu LS. Traditional Chinese medicine for the treatment of chronic prostatitis in China: a systematic review and meta-analysis. J Altern Complement Med. 2006;12(8):763-769.

11. Xiong GB, Qiu MX, Gong BS, Wang JY, Zhang SW. Systemic review of Chinese herbs of activating blood and dispelling stasis for chronic prostatitis. Chin J Surg Integr Tradit West Med. 2008;14:532-536. Chinese.

12. Qiu MX, Xiong GB, Zhou SY, Wang D, Shao JC, Wang JY. [Qingrelishi-category Chinese medicine for chronic prostatitis: a systematic review]. Zhonghua nan ke xue/Natl J Androl. 2007;13:370-377. Chinese.

13. Banares R, Albillos A, Rincon D, et al. Endoscopic treatment versus endoscopic plus pharmacologic treatment for acute variceal bleeding: a meta-analysis. Hepatology. 2002;35(3):609-615.

14. Bian Z, Liu B, Moher D, et al. Consolidated standards of reporting trials (CONSORT) for traditional Chinese medicine: current situation and future development. Front Med. 2011;5(2):171-177.
15. Li S, Zhang ZQ, Wu LJ, Zhang XG, Li YD, Wang YY. Understanding Zheng in traditional Chinese medicine in the context of neuroendocrine-immune network. IET Syst Biol. 2007;1(1):51-60.

16. Medicine. APcoCITaW. Guideline of integrated traditional and western medicine in the diagnosis and treatment of chronic prostatitis (trial version). Chin J Integrat Tradit Chin West Med. 2007;27: 1052-1056.

17. Chen GH, Song JQ, Li HS, et al. Multi-centered randomize-controlled clinical study on TCM treatment for chronic prostatitis. $J$ Tradit Chin Med. 2010;51:419-422.

18. Gao GQ, Song JQ, LU JX, et al. Clinical evaluation studies on TCM in the treatment of chronic prostatitis. Chin J Basic Med Tradit Chin Med. 2014;20:1394-1401.

19. Schmeller T, Latz-Bruning B, Wink M. Biochemical activities of berberine, palmatine and sanguinarine mediating chemical defence against microorganisms and herbivores. Phytochemistry. 1997;44(2): 257-266.

20. Kuo CL, Chi CW, Liu TY. The anti-inflammatory potential of berberine in vitro and in vivo. Cancer Lett. 2004;203(2):127-137.

21. Fukuda K, Hibiya Y, Mutoh M, Koshiji M, Akao S, Fujiwara H. Inhibition by berberine of cyclooxygenase- 2 transcriptional activity in human colon cancer cells. J Ethnopharmacol. 1999;66(2):227-233.

22. Yao WX. The effect of berberine on vas deferens and anococcygeal muscle in rats. Acta Pharmacol Sin. 1986;7:196.

23. Hu HJ, Qi GR, Chen YX, Zhou RH. Anticoagulation of Herb Lycopus lucidus. Pharmacol Clin Chin Mater Med. 1995;6:28-31.

24. Shrimali D, Shanmugam MK, Kumar AP, et al. Targeted abrogation of diverse signal transduction cascades by emodin for the treatment of inflammatory disorders and cancer. Cancer Lett. 2013;341(2): 139-149.

25. Cao F, Peng W, Li X, et al. Emodin is identified as the active component of ether extracts from Rhizoma Polygoni Cuspidati, for anti-MRSA activity. Can J Physiol Pharmacol. 2015;93(6):485-493.

26. Vickers A, Goyal N, Harland R, et al. Do certain countries pro-duce only positive results? A systematic review of controlled trials. Control Clin Trials. 1998;19:159-166.

27. Simon SD. Statistical Evidence in Medical Trials: What Do the Data Really Tell Us?. Oxford: Oxford University Press; 2006. [ISBN 978-0-19-856761-5:122].

28. Gao Z, Shao KQ, Shen JW, et al. Clinical Observation on Longbi Xintong Granule of Different Dosage for Chronic Prostatitis. Journal of Traditional Chinese Medicine. 2012;53:1570-1576.

29. Mao PM. Surgery of Chinese Medicine (Andrology). Beijing: Beijing University of Chinese Medicine, 2014.

30. Zhang JY, Liu HX, He JH, et al. The efficacy and safety of Compound Huangkui Granule in Treating Chronic nonbacterial Prostatitis of Damp-heat and stagnation syndrome. Acta Chinese Medicine and Pharmacology. 2014;42:115-117.

31. Jin S, Hu SY, He JH, et al. The efficacy of Qianlie Xiaoyan Zhitong tablet in Treating Chronic nonbacterial Prostatitis of Damp-heat and stagnation syndrome. Journal of new Chinese Medicine. 2011;43: $78-80$.

32. Zhou Z. Treating Chronic Prostatitis of dampness-heat and blood stasis. Chengdu: Chengdu University of Chinese Medicine, 2002.

33. Gao XS, Gao WX, He JQ, et al. The effiecey and safety of Longqing tablet in the treatment of Chronic Prostatitis: a multi-center, randomized, double-blind, placebo-controlled clinical trial. Chinese Journal of Andrology. 2010;24:21-25.

34. Hou XM. Treating Chronic Prostatitis with damp-heat mixed blood. Chengdu: Chengdu University of Chinese Medicine, 2011.

35. Xu G, Ding Q, Gao XF, et al. The efficacy and safety of Wenglitong tablet in Treating Chronic Prostatitis: a multi-center, randomized, double-blind, placebo-controlled clinical trial. Chinese Journal of Urology. 2005;26:781.

36. Guo K, Zeng ZG, Huang Y, Ou XY, He Y. Double-blind Randomized Controlled Trial of Qian lieantong Tablets in the Treatment of Chronic Pelvic Pain Syndrome. Liaoning Journal of Traditional Chinese Medicine. 2007;34:1215-1216. 
37. Gao XS, Gao WX, He JQ, et al. Multi-center, Positive-drug, placebocontrolled clinical trial of Qianlie Miniao Shuan in treating Chronic Prostatitis. Chinese Journal for Clinicians. 2010;38:36-38.

38. Li LQ, Gao XS, Gao WX, et al. The efficacy and safety of ProstantTM in the treatment of chronic prostatitis: a multi center, randomized, double blind, placebo controlled clinical trial. Chin J Urol. 2003;23:780-783.

39. Xu G, Lu J, Tang XD, et al. The efficacy and safety of ProstantTM in the treatment of chronic prostatitis: a multi center, randomized, double blinded, placebo controlled trial. Chin J Urol. 2002;23:296-298.

40. Yao RZ, Xie YQ, Xie JX, Cheng YX, Qiu YC. Efficacy Observation of Fat-soluble Prostant on Chronic Prostatitis Due to Damp Heat Stagnation. World Journal of Integrated Traditional and Western Medicine. 2008;3:720-724.

41. Jia J, Xue C, Zhang S, Lu Y, Zheng D. Efficacy and Safety of Qianliean Suppository in the Treatment of Chronic Prostatitis. National Journal of Andrology. 2001;7:417-419.
42. Wang Y, You Z, Zhang D. Clinical Study of Prostant in Treating Chronic Prostatitis. Chinese Journal of Hemorheology. 2010;20:613-615.

43. Yin F, Pang B, Wang P, Ju Y, Tang Z. Efficacy of Qianliean Suppository in the Treatment of Chronic Prostatitis. Practical Journal of Medicine. 2002;18:1336-1337.

44. Ju W, Wang J. The curative effects of the Qianliexiaoyanzhitong tablet in treating the chronic prostatitis of TCM syndrome of stagnant dampness-heat. Chengdu University of Traditional Chinese Medicine Thesis. 2009;4:1-116.

45. Zhou Z, Yang J, Gao W. The effects of Wenglitong capsule in the treatment of chronic pelvic pain syndrome. JNoth China Coal Medical College. 2003;5(4):431-432.

\section{Publish your work in this journal}

Patient Preference and Adherence is an international, peer-reviewed, open access journal that focuses on the growing importance of patient preference and adherence throughout the therapeutic continuum. Patient satisfaction, acceptability, quality of life, compliance, persistence and their role in developing new therapeutic modalities and compounds to optimize clinical outcomes for existing disease states are major areas of interest for the journal. This journal has been accepted for indexing on PubMed Central. The manuscript management system is completely online and includes a very quick and fair peer-review system, which is all easy to use. Visit http://www dovepress.com/testimonials.php to read real quotes from published authors. 